\title{
Kinetics of crystal nucleation in ionic solutions: Electrostatics and hydration forces
}

\author{
Magdalena Kowacz $^{\mathrm{a}, *}$, Manuel Prieto ${ }^{\mathrm{b}}$, Andrew Putnis ${ }^{\mathrm{a}}$ \\ ${ }^{a}$ Institut für Mineralogie, Universität Münster, Correnstrasse 24, 48149 Münster, Germany \\ ${ }^{\mathrm{b}}$ Departamento de Geología, Universidad de Oviedo, C/Jesús Arias de Velasco, s/n, 33005 Oviedo, Spain
}

Received 29 May 2009; accepted in revised form 14 October 2009; available online 21 October 2009

\begin{abstract}
The heat of precipitation, the mean crystal size and the broadness of crystal size distribution of barium sulfate precipitating in aqueous solutions of different background electrolytes $(\mathrm{KCl}, \mathrm{NaCl}, \mathrm{LiCl}, \mathrm{NaBr}$ or $\mathrm{NaF}$ ), was shown to vary at constant thermodynamic driving force (supersaturation) and constant ionic strength depending on the salt present in solution. The relative inversion in the effect of respective background ions on the characteristics of barite precipitate was observed between two studied supersaturation $(\Omega)$ and ionic strength (IS) conditions. The crystal size variance $\left(\beta^{2}\right)$ increased in the presence of background electrolytes in the order $\mathrm{LiCl}<\mathrm{NaCl}<\mathrm{KCl}$ at $\Omega=10^{3.33}$ and $\mathrm{IS}=0.03 \mathrm{M}$ and $\mathrm{KCl}<\mathrm{NaCl}<\mathrm{LiCl}$ at $\Omega=10^{3.77}$ and IS $=0.09 \mathrm{M}$. At a given $\Omega$ and IS the respective size of barite crystals decreased with increasing $\beta^{2}$ in chloride salts of different cations and remained constant in sodium salts of different anions.

We suggest that ionic salts affect the kinetics of barite nucleation and growth due to their influence on water of solvation and bulk solvent structure. This idea is consistent with the hypothesis that the kinetic barrier for barium sulfate nucleation depends on the frequency of water exchange around respective building units that can be modified by additives present in solution. In electrolyte solution the relative switchover between long range electrostatic interactions and short range hydration forces, which influence the dynamics of solvent exchange between an ion solvation shell and bulk fluid, results in the observed inversion in the effect of differently hydrated salts on nucleation rates and the resulting precipitate characteristics.
\end{abstract}

(C) 2009 Elsevier Ltd. All rights reserved.

\section{INTRODUCTION}

The specific chemistry of a solvent can affect crystal growth and nucleation kinetics, morphology, crystal size distribution and purity of precipitates. In an aqueous solvent, step spreading velocity and rates of surface nucleation have been recognized to depend on ion and surface hydration characteristics. Kinetics of attachment of molecules to a growing phase during crystallization and other phase transition processes have been shown to be limited by the activation energy for diffusion that can result from the need to expel waters attached to the incoming molecules and to the growth site (Petsev et al., 2003). The kinetics of new kink for-

\footnotetext{
* Corresponding author. Tel.: +49 2518333487.

E-mail address: magdakowacz@uni-muenster.de (M. Kowacz).
}

mation (surface nucleation) was hypothesized to depend on the frequency of water exchange between a building unit and a bulk fluid (Kowacz and Putnis, 2008). It has been shown that changing the properties of the aqueous solvation environment by organic additives as well as simple inorganic salts can result in modification of the reaction rates as well as modes of crystal dissolution and growth, surface features, bulk crystal morphology and impurity incorporation even if the thermodynamic driving force is kept constant (De Yoreo and Dove, 2004; Dove et al., 2005; Piana et al., 2006, 2007; Kowacz et al., 2007). The influence of the ionic strength on precipitation kinetics was found to be in agreement with the Bronsted-Bjerrum theory that relates reaction rates with polar properties of the solvent (salt medium effect) and the consequential hydration of ions (Zuddas and Mucci, 1998). The origin of salt-specific effects at constant ionic strength was explained by the fact that the phenomenon of ionic 
strength itself is determined by the water affinity of particular ions (Collins et al., 2007). Consistent with this idea is that the effect of additives on surface processes was recently suggested to result from their influence on solvent structure and dynamics in solvation shells and in the bulk, and not necessarily from specific interactions between species present in solution and the crystal face (Elhadj et al., 2006; Kowacz and Putnis, 2008; Stephenson et al., 2008). Such a concept creates some common framework relating fluid properties and mineral precipitation/dissolution behavior. Recognition of the relation between solution composition, aqueous solvent properties and mineral crystallization can add to our understanding of phase transition processes in multicomponent natural solutions such as seawater or body fluids. It is also of importance for medical and industrial purposes such as inhibition of pathological mineralization, preventing scale formation or designing a product with desirable characteristics such as defined size, morphology and narrow size distribution. Crystal size and crystal size distribution affect dissolution rates and eventual bioavailability, and thus, for example, determine formulation strategies of pharmaceutical products.

This study is concerned with three-dimensional nucleation in multicomponent electrolyte solutions. For the nucleation event to take place in solution, the dissolved ions have to come into contact to form pairs, clusters or aggregates. Association of ions is promoted by the tendency of an aqueous solvent to preserve its hydrogen-bonded network (Hawlicka and Swiatla-Wojcik, 2003). The more structured the solvent the higher its tendency to exclude ions in order to preserve the integrity of the network. Structure (and mobility) of the aqueous solvent depends on solution composition (hydration of solutes and/or the effect of cosolvents) (Hawlicka and Swiatla-Wojcik, 2003; Marcus, 2009). In order to associate, ions have to lose some of their hydration water. Therefore the facility to exchange the water molecules between a solvation shell and the bulk solution also assists association. Dynamics of the solvation shells is affected by the electric fields and hydration properties of the other solutes present in solution (Rull and Ohtaki, 1997; Palka and Hawlicka, 2005). Ion association in solution, the prerequisite for nucleation, depends then on the dynamic and structural characteristics of solvent-solvent and ion-solvent interactions, these being defined by solution composition.

The aim of this work is to investigate the effect of simple ionic salts on three-dimensional nucleation in solution from the perspective of the influence of the electrolytes on solvent structure and on flexibility of ion hydration shells. We present experimental results of barium sulfate precipitation in aqueous solutions of different background electrolytes and address kinetics of nucleation and the resulting characteristics of the precipitate. Electrolyte solution concentrations were adjusted to obtain conditions for which the action of background ions is determined either mainly by their electrostatic influence on ion-water interactions (low ionic strength) or by the effect of their hydration on solvent-solvent interactions (high ionic strength). The composition of background salts was selected to produce distinct electrostatic and hydration characteristics. A calorimetric study on the enthalpy of solution of barium chloride in selected background electrolytes provided information on the energetical effects of modifying the composition of the aqueous solvent on the solvation of $\mathrm{Ba}^{2+}$ ions.

\section{METHODS AND MATERIALS}

\subsection{Experimental procedure}

Precipitation experiments were performed in a solution calorimeter (PARR 6755) equipped with a PARR 6772 high-precision thermometer. The experiments were carried out at constant room temperature $\left(25 \pm 1{ }^{\circ} \mathrm{C}\right)$ using deionized (MilliQ) water. Each experiment was repeated at least six times. The Dewar flask was filled with $100 \mathrm{ml}$ of $0.033 \mathrm{M}$ or $0.1 \mathrm{M}$ electrolyte solution $(\mathrm{KCl}, \mathrm{NaCl}, \mathrm{LiCl}, \mathrm{NaBr}$ or $\mathrm{NaF}$ ) containing $\mathrm{Na}_{2} \mathrm{SO}_{4}$. Ten milliliter of solution containing $\mathrm{BaCl}_{2}$ in deionized water was loaded into a glass cell sealed with a detachable Teflon dish. The cell was immersed into the Dewar and rotated by an external electric motor. As soon as thermal equilibrium was achieved, the glass cell was opened and the reactants were mixed. The measured temperature change $(\Delta T c)$ due to the exothermic crystallization was used to calculate the heat of barium sulfate precipitation $\left(Q_{\mathrm{BaSO} 4}\right)$ in respective background salts. $\Delta T c$ was converted to heat $\left(Q_{\mathrm{BaSO} 4}\right)$ by multiplying $\Delta T c$ by the energy equivalent $(e)$ of the calorimeter and its contents: $Q_{\mathrm{BaSO} 4}=\Delta T c \cdot e$ ( $e$ was derived by a pre-experimental standardization process). Immediately after the crystallization reaction had taken place (as indicated by abrupt temperature change followed by lag period) $15 \mathrm{ml}$ of the resulting solution was filtered through a filter with $0.45 \mu \mathrm{m}$ pore diameter. The filtrate was then analyzed with ICP-AES (inductively coupled plasma atomic emission spectroscopy) using an iCAP 6000 (Thermo) plasma spectrometer for $\left[\mathrm{Ba}^{2+}\right]$ concentration. The precipitate remaining on the filter was imaged by scanning electron microscopy (SEM) and analyzed by X-ray diffraction. Heat of dilution of the $\mathrm{BaCl}_{2}$ solution (from 10 to $110 \mathrm{ml}$ ) in the solution of background electrolyte was equal within an experimental error for all of the background salts and therefore the heat of dilution was not included in the calculation of $Q_{\mathrm{BaSO}}$. The calorimetric data reported in this work are then used to compare the relative effects of different background electrolytes and not to derive absolute values. The enthalpy of $\mathrm{BaSO}_{4}$ precipitation $\left(\Delta H_{\mathrm{ppt}}\right)$ was calculated as: $\Delta H_{\mathrm{ppt}}=\left(-Q_{\mathrm{BaSO} 4}\right) / N$, where $N$ is the number of moles of $\mathrm{BaSO}_{4}$ determined by comparing the final concentrations of barium in the aqueous solution to their initial values (under assumption that all the $\left[\mathrm{Ba}^{2+}\right]$ consumed during the crystallization process is taken up by the stoichiometric precipitation of $\mathrm{BaSO}_{4}$ ).

The solution composition, the supersaturation $(\Omega)$ with respect to barium sulfate, the experimentally determined $Q_{\mathrm{Ba}}$ so4, $\Delta H_{\mathrm{ppt}}$ and the measured concentration of $\left[\mathrm{Ba}^{2+}\right]$ left in solution after the crystallization process are presented in Table 1. The error in the final barium concentrations represents the reproducibility involved in the whole precipitation procedure. The saturation state is expressed as $\Omega=\mathrm{IAP} / K_{\mathrm{sp}}$ (IAPion activity product; $K_{\mathrm{sp}}$ - solubility product). The computer program PHREEQC (Parkhurst and Appelo, 1999) was used to calculate the saturation index $\mathrm{SI}=\log \left(\mathrm{IAP} / K_{\mathrm{sp}}\right)$ and ionic 


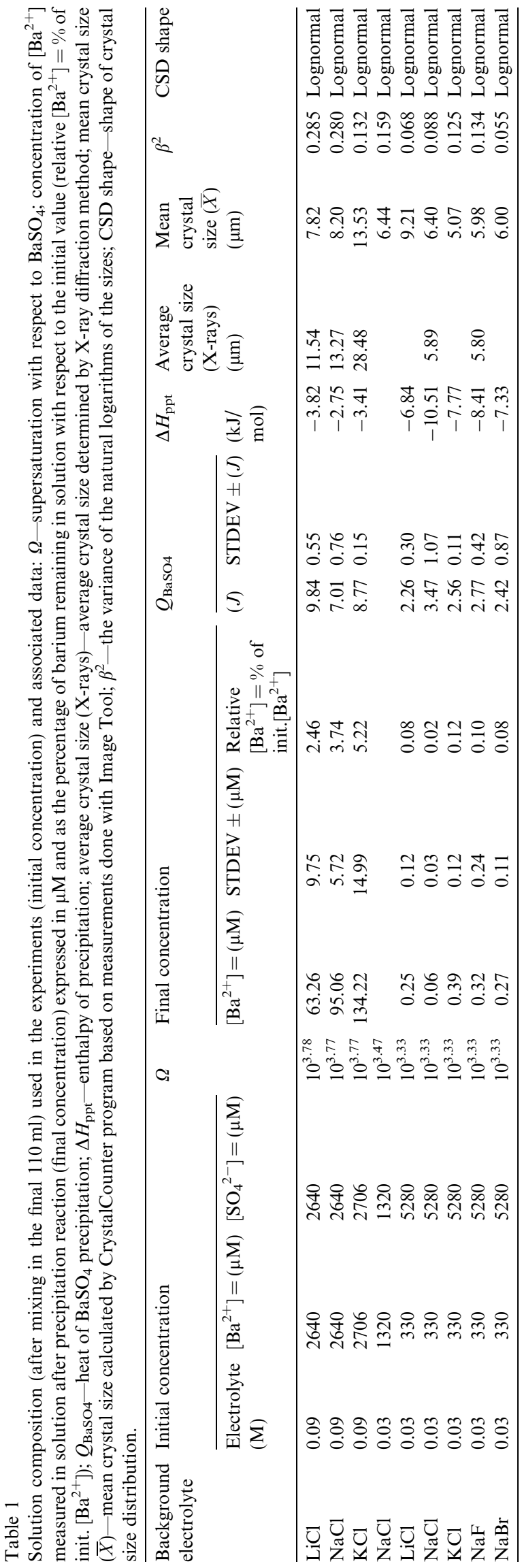

Table 2

Enthalpy of solution of $\mathrm{BaCl}_{2} \times 2 \mathrm{H}_{2} \mathrm{O}\left(\Delta H_{\mathrm{BaCl} 2}\right)$ in electrolyte solutions.

\begin{tabular}{lll}
\hline Electrolyte & & $\Delta H_{\mathrm{BaCl} 2}$ \\
\hline Type & Conc. $=(\mathrm{M})$ & $(\mathrm{kJ} / \mathrm{mol})$ \\
\hline $\mathrm{LiCl}$ & 0.1 & 15.53 \\
$\mathrm{NaCl}$ & & 13.57 \\
$\mathrm{KCl}$ & & 14.08 \\
$\mathrm{LiCl}$ & 0.03 & 13.33 \\
$\mathrm{NaCl}$ & & 12.61 \\
$\mathrm{KCl}$ & & 14.44 \\
\hline
\end{tabular}

strength (IS). The concentration of $\left[\mathrm{Ba}^{2+}\right]$ and $\left[\mathrm{SO}_{4}{ }^{2-}\right]$, background salts and $\Omega$ express concentrations of species and the saturation state of the system that would be achieved in case of complete mixing of working solutions in the final $110 \mathrm{ml}$ of solution. Nevertheless it is worth noting that supersaturation in fact develops during the time of the mixing process. Moreover $\left[\mathrm{Ba}^{2+}\right]$ in solution is initially concentrated in a volume ten times smaller than the $\left[\mathrm{SO}_{4}{ }^{2-}\right]$. As a result the actual $\Omega$ in a real reaction time can be different from the calculated "nominal supersaturation".

The enthalpy of solution of barium chloride dihydrate $\left(\mathrm{BaCl}_{2} \times 2 \mathrm{H}_{2} \mathrm{O}\right)$ in selected background electrolytes was determined by loading a glass cell of the calorimeter with a $0.15 \mathrm{~g}$ sample of solid $\mathrm{BaCl}_{2} \times 2 \mathrm{H}_{2} \mathrm{O}$ and dissolving the solid in the Dewar flask containing $100 \mathrm{ml}$ of $0.03 \mathrm{M}$ or $0.1 \mathrm{M} \mathrm{KCl}, \mathrm{NaCl}$ or $\mathrm{LiCl}$ aqueous solution. The calculated heat of solution $\left(Q_{\mathrm{BaCl} 2}=\Delta T c \cdot e\right)$ was converted to enthalpy of solution $\left(\Delta H_{\mathrm{BaCl} 2}\right)$ according to the formula: $\Delta H_{\mathrm{BaCl} 2}=(-Q \mathrm{BaCl}) / N$, where $Q_{\mathrm{BaCl} 2}$ is expressed in $\mathrm{kJ}$ and $N$ in moles of $\mathrm{BaCl}_{2} \times 2 \mathrm{H}_{2} \mathrm{O}$. $\Delta \mathrm{H}_{\mathrm{BaCl} 2}$ provides information about the solvation of $\mathrm{Ba}^{2+}$ in aqueous solutions of different chloride salts. The results are presented in Table 2.

\subsection{Average crystal size}

The average size of the crystals obtained in the precipitation experiments was determined from two-dimensional $\mathrm{X}$ ray diffraction patterns collected using a single-crystal diffractometer equipped with an X-ray area detector (CCD). $\mathrm{X}$-ray area detectors were initially used for protein crystallography in the 1980s, but more recently their use has been extended to a number of applications, including the study of polycrystalline materials (He, 2005). Two-dimensional diffraction patterns of polycrystalline samples consist of concentric (Debye-Scherrer) rings associated with different Bragg reflections. Each ring is produced by the superposition of reflections of many crystals illuminated by the X-ray beam, all of them with a set of $(h k l)$ crystallographic planes oriented to fulfil the Bragg condition. These 2D-diffraction patterns can be converted into conventional diffractograms ( $2 \theta$-scans) by radial integration of pixel intensities. These conventional diffractograms can be processed as usual for mineral phase identification, crystallinity and crystallite size measurements, refinement of cell parameters, etc. However, the 2D-diffraction pattern contains additional information about the grain size, the existence of preferential orientations, and other textural features. 
For instance, depending on the specific characteristics of the sample, the rings can be continuous or spotty. When a ring is spotty, the variation of intensity along a ring associated with a given $h k l$ reflection ( $\psi$-scan) gives an intensity profile (after azimuthal integration) with a series of peaks. In a $\psi$-scan, each peak corresponds to the reflection from an individual crystal with the corresponding $(h k l)$ planes oriented to fulfil the Bragg condition. These $\psi$-scan peak intensities depend on the crystal size: as the average crystal size increases, the peak intensities increase and the number of peaks decreases. From the average intensity of these peaks and using a calibration curve obtained with standard samples, the crystal size can be determined. It is worth noting that the crystal size determined in this way represents the real average physical size, a parameter that may be com- pletely different from the so-called crystallite size. The crystallite size is an XRD term that indicates the size of a coherently diffracting domain and thus does not necessarily coincide with the crystal size. This latter parameter is usually determined by considering the full width at half maximum of a given reflection in a conventional $2 \theta$-scan.

Here, the two-dimensional X-ray diffraction patterns of the precipitates have been obtained using an Oxford Diffraction Xcalibur Nova single-crystal diffractometer equipped with a CCD area detector Onyx $(165 \mathrm{~mm})$ and $\mathrm{Cu}-\mathrm{K} \alpha$ radiation. The precipitate samples were glued to a fibre (the type commonly used for mounting single crystals) and placed at a distance to the detector of $65 \mathrm{~mm}$. The 2Dpatterns (Fig. 1a) were then studied using the XRD2DScan software (Rodríguez-Navarro, 2006). The samples were first
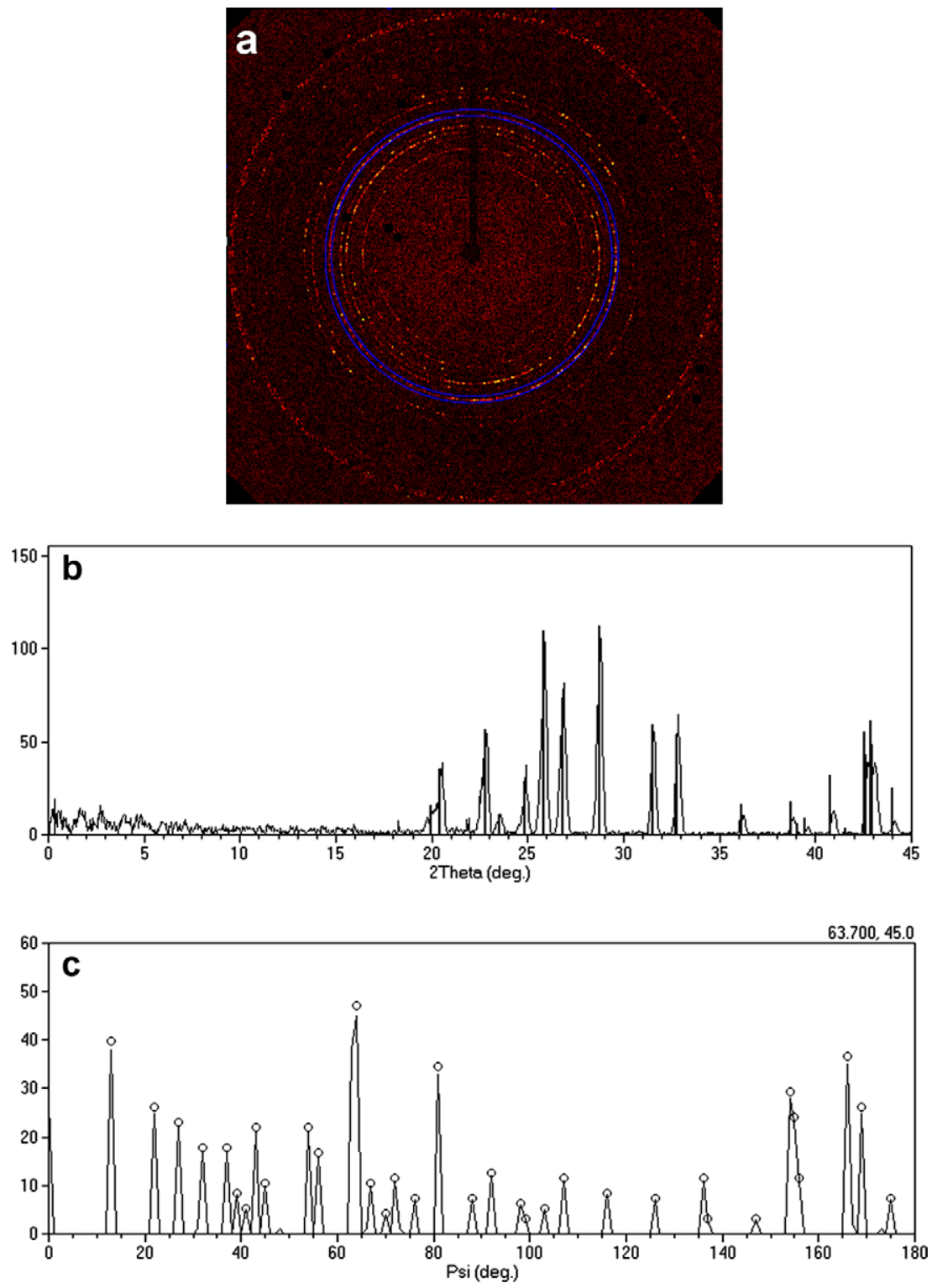

Fig. 1. (a) Two-dimensional diffraction pattern of a sample of the precipitate obtained in experiment 331-Na. The blue line delimits a ring

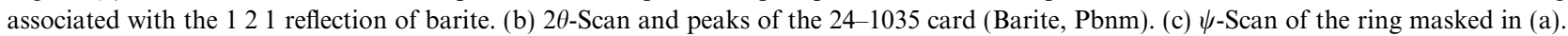
(For interpretation of color mentioned in this figure the reader is referred to the web version of the article.) 
indentified to be barite by analyzing the reflections in a conventional $2 \theta$-scan diffractogram (Fig. 1b). Then, in order to perform the crystal size study, the reflection 121 $\left(2 \theta=28.744^{\circ}\right)$ was selected. This is one of the three main reflections of barite and is usually very well defined in the diffractograms. Fig. 1c shows the variation of intensity along the $121 \mathrm{ring}$ as a function of the $\psi$-angle (from 0 to $180^{\circ}$ ) in the case of the sample $331-\mathrm{Na}$. These $\psi$-scans were calculated by integrating pixel intensities within a $2 \theta$ range from $\sim 28.4^{\circ}$ to $\sim 29.3^{\circ}$. The XRD2DScan software determines the number of peaks and the average peak intensity. From this average value, and using a calibration curve, the average crystal size can be determined. Here, this calibration curve was obtained using barite grains of known size. Table 1 shows the crystal sizes determined in this way.

\subsection{Crystal size distribution (CSD)}

SEM images of the barium sulfate precipitate were processed with the UTHSCSA Image Tool computer software (developed at the University of Texas Health Science Center at San Antonio, Texas and available from the Internet by anonymous FTP from maxrad6.uthscsa.edu) to determine the sizes of the individual barite crystals representative for the size distribution of the crystals that precipitated in different electrolytes. In all experiments the resulting precipitate has a plate-like morphology (Fig. 2) and therefore the area of the best expressed crystal face was used in this work as an indication of the relative size of the crystal. Crystal size was then described by the diameter of the square with the same area as the measured area of the respective crystal face. The crystal diameters estimated in this way (approximately 100 for each sample) were used to generate crystal size distributions with the program CrystalCounter (Eberl et al., 2000). The program calculates CSD shape, the mean crystal size $\left(\bar{X}=\sum X f(X)\right.$, where $f(X)$ is the frequency of group size $X)$, the mean of the natural logarithms of the sizes $\left(\alpha=\sum \ln (X) f(X)\right)$, and the variance of the natural

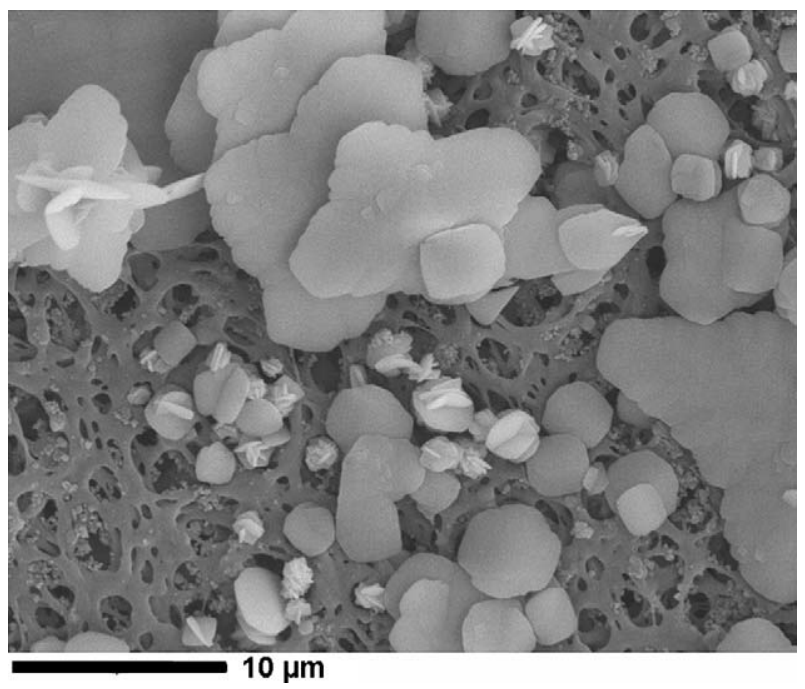

Fig. 2. SEM image showing barite crystals precipitated in the presence of $0.09 \mathrm{M} \mathrm{NaCl}$ as background electrolyte.

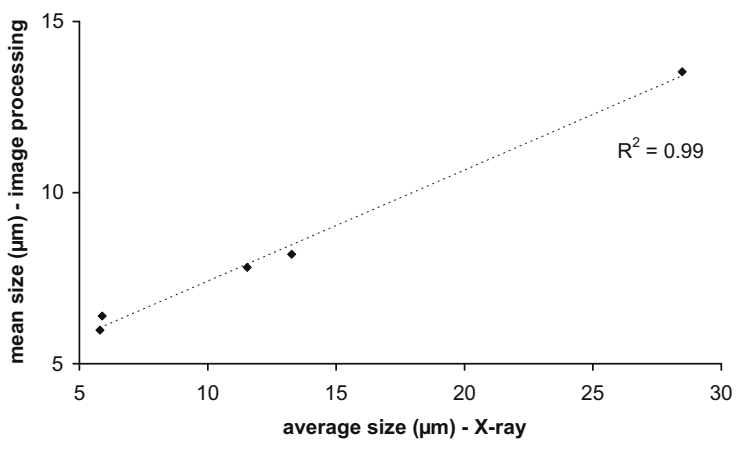

Fig. 3. Correlation between mean crystal size $(\bar{X})$ and average crystal size of barium sulfate precipitate derived by image processing and X-ray diffraction method, respectively.

logarithms of the sizes $\left(\beta^{2}=\sum(\ln X-\alpha)^{2} f(X)\right)$. According to the approach proposed by Eberl et al. (1998), CSD shapes can be related to the crystal growth mechanism. Three basic CSD shapes corresponding to different growth modes are: (a) an asymptotic CSD produced in systems with constant-rate nucleation followed by size-dependent (proportional) surface controlled growth; (b) universal, steady-state curve attributed to Ostwald ripening, and (c) lognormal (one of the most common CSD in natural systems (Eberl et al., 2002)) generated by a crystal growth mechanism having decaying-rate nucleation accompanied by size-dependent growth. Size-dependent growth means that crystal growth rate is proportional to the initial crystal size, so that larger crystals grow faster than smaller crystals leading to increasing crystal size variance $\left(\beta^{2}\right)$ with time. Calculated mean crystal sizes $(\bar{X})$, crystal size variance $\left(\beta^{2}\right)$ and CSD shapes are reported in Table 1.

Because of the complex morphology of the crystals, sizes determined by image processing (IP) are not a very accurate expression of the actual dimensions of the crystalline material. Therefore for selected samples, calculated mean crystal sizes determined from SEM images were compared with average crystal sizes determined by the X-ray diffraction method. The X-ray method probably gives a better estimation of the actual mean crystal size, but it has the disadvantage that does not allow estimating the CSD. Thus, as we need to determine the CSD we have used the IP method and the X-ray method is used just to check if there is a good correlation with the mean sizes obtained by the IP. The trends in the relative differences in sizes of the crystals that precipitated in respective background electrolytes at given experimental conditions are in good agreement between the two methods (Fig. 3). The actual values are different, but sizes obtained by X-ray diffraction correlate with real crystal volume, while those based on image processing correlate with the area of the imaged faces only.

\section{RESULTS}

In all our experiments barium sulfate crystals are lognormally distributed (Table 1 and Fig. 4) implying a common nucleation and growth mechanism (Eberl et al., 1998). At the same time crystal size $(\bar{X})$ and broadness of crystal size distribution $\left(\beta^{2}\right)$ vary at constant ionic strength 


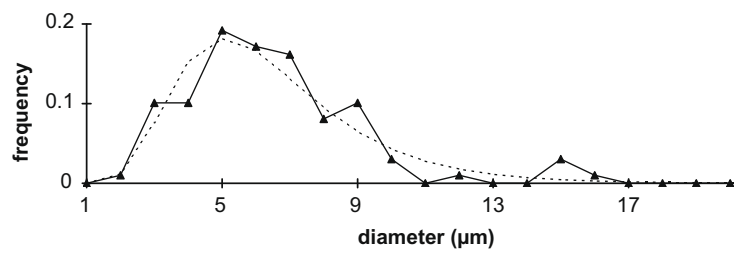

Fig. 4. Example of the crystal size distribution (CSD) of barium sulfate precipitated in $0.03 \mathrm{M} \mathrm{NaCl}$ as a background electrolyte. Lognormal distribution was verified by the K-S (KolmogorovSmirnov) statistical test that compares CSD generated by CrystalCounter (Eberl et al., 2000) based on the introduced data (solid line) with theoretical lognormal CSD (dashed line).

(IS) and constant thermodynamic driving force (supersaturation) depending on the background electrolyte present in solution (Table 1). The specific correlations are outlined below and presented explicitly in Fig. 5.

Chloride electrolytes (with different cations: $\mathrm{Li}^{+}, \mathrm{Na}^{+}$ and $\mathrm{K}^{+}$):

1. At $\Omega=10^{3.33}$ and IS $=0.03 \mathrm{M}, \beta^{2}$ increases in the order $\mathrm{LiCl}<\mathrm{NaCl}<\mathrm{KCl}$.

2. At $\Omega=10^{3.77}$ and IS $=0.09 \mathrm{M}, \beta^{2}$ increases in the order $\mathrm{KCl}<\mathrm{NaCl}<\mathrm{LiCl}$, that is, the effect is the reverse.

3. With $\mathrm{KCl}$ as background electrolyte the mean crystal size $(\bar{X})$ is considerably larger at $\Omega=10^{3.77}$ (and IS $=0.09 \mathrm{M}$ ) than at $\Omega=10^{3.33}$ (and IS $=0.03 \mathrm{M}$ ).

4. With $\mathrm{NaCl}$ as background electrolyte the mean crystal size $(\bar{X})$ is only slightly larger at $\Omega=10^{3.77}$ (and IS $=0.09 \mathrm{M}$ ) than at $\Omega=10^{3.33}$ (and IS $=0.03 \mathrm{M}$ ). (At constant IS $=0.03 \mathrm{M}$ changing $\Omega$ does not seem to affect $\bar{X})$.

5. With $\mathrm{LiCl}$ as background electrolyte the mean crystal size $(\bar{X})$ is smaller at $\Omega=10^{3.77}$ (and IS $=0.09 \mathrm{M}$ ) than at $\Omega=10^{3.33}$ (and IS $=0.03 \mathrm{M}$ ) (the effect is the reverse to that of $\mathrm{KCl}$ ).

6. For a given supersaturation $\left(\Omega=10^{3.33}\right.$ or $\left.\Omega=10^{3.77}\right)$ and IS the mean crystal size $(\bar{X})$ decreases with increasing $\beta^{2}$.

7. For a given background electrolyte, $\beta^{2}$ increases with increasing $\Omega$ and IS. The effect is less marked with $\mathrm{KCl}$.

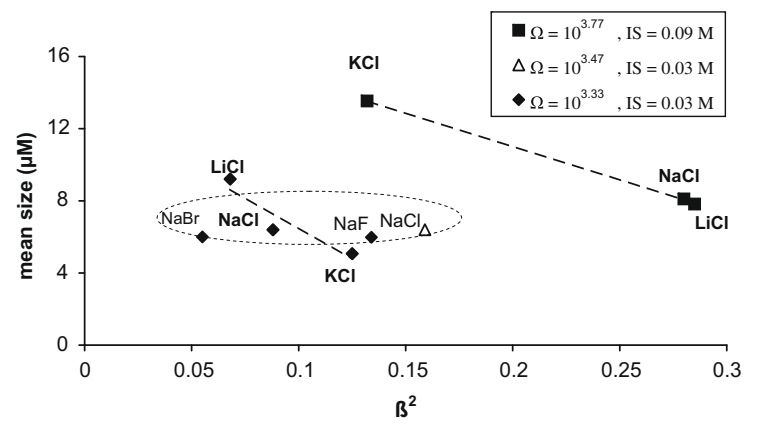

Fig. 5. Mean crystal size $(\bar{X})$ of barium sulfate precipitate at different supersaturation $(\Omega)$ and IS conditions as a function of crystal size variance $\left(\beta^{2}\right)$. The dashed lines show the tendencies for different chlorides, whereas the short-dash ellipse shows the tendency for different sodium halides.
Sodium electrolytes (with different anions: $\mathrm{Br}^{-}, \mathrm{Cl}^{-}$and $\left.\mathrm{F}^{-}\right)$:

8. At $\Omega=10^{3.33}$ and IS $=0.03 \mathrm{M}$ the mean crystal size $(\bar{X})$ is virtually the same for all the three electrolytes.

9. $\beta^{2}$ depends on the background salt type, increasing in the order $\mathrm{NaBr}<\mathrm{NaCl}<\mathrm{NaF}$.

The enthalpy of precipitation of barium sulfate depends on the background electrolyte and is less negative at higher $\Omega$ and IS (Table 1). The enthalpy of precipitation is given by: $\Delta H_{\mathrm{ppt}}=U\left(\mathrm{BaSO}_{4}\right)-\Delta H_{\text {hyd }}\left(\mathrm{Ba}^{2+}\right)-\Delta H_{\text {hyd }}\left(\mathrm{SO}_{4}^{2-}\right)$, where $U\left(\mathrm{BaSO}_{4}\right)$ is the lattice energy, $\Delta H_{\mathrm{hyd}}\left(\mathrm{Ba}^{2+}\right)$ and $\Delta H_{\text {hyd }}\left(\mathrm{SO}_{4}{ }^{2-}\right)$ are the enthalpies of hydration of the ions. Because lattice energy does not depend on solution composition, the less negative $\Delta H_{\mathrm{ppt}}$ implies higher energy expended on dehydration of the ions (enhanced ion-water attraction) at higher IS.

Enthalpy of solution of $\mathrm{BaCl}_{2} \times 2 \mathrm{H}_{2} \mathrm{O}\left(\Delta H_{\mathrm{BaCl} 2}\right)$ depends on the ionic strength and on the salt type (Table 2). $\Delta H_{\mathrm{BaCl} 2}$ results from the energy expended on breaking solute-solute bonds (here constant lattice energy) and solvent-solvent interactions and the energy gain on ion solvation. Therefore, as the energy involved in solute-solute bonds does not depend on the background electrolyte, $\Delta H_{\mathrm{BaCl} 2}$ in different chloride salts is expected to be an indication of the relative changes of water-water vs. bariumwater interactions in respective electrolytes. Consequently less positive $\Delta H_{\mathrm{BaCl} 2}$ at higher $\mathrm{KCl}$ concentration implies more energetically favorable hydration of $\mathrm{Ba}^{2+}$ while more positive $\Delta H_{\mathrm{BaCl} 2}$ at higher $\mathrm{NaCl}$ and $\mathrm{LiCl}$ concentration indicates less favorable hydration of $\mathrm{Ba}^{2+}$ at higher IS. The hydration in this context is defined by the relative difference in the affinity of water to the ion and the affinity of water to other water molecules (Samoilov, 1965).

\section{DISCUSSION}

The observed dependence of the characteristics of the solid $\left(\beta^{2}\right.$ and $\bar{X}$ ) precipitated at constant $\Omega$ (by a common mechanism as indicated by CSD shape) on the solution composition (Fig. 5) can be explained by considering differences in the reaction kinetics. A lognormal distribution of barium sulfate crystals precipitated in our experiments indicates that crystals were generated in systems with a decaying nucleation rate accompanied by size-dependent crystal growth (Kile et al., 2000). Such a crystal size distribution suggests that nucleation and growth is controlled by advection rather than diffusion of the reactants (Kile and Eberl, 2003). In the our experimental procedure supersaturation $(\Omega)$ buildup starts after mixing the working solutions. The theoretical supersaturation level that could be achieved in the system is very high. However, because of a very short induction period the actual $\Omega$ cannot exceed the threshold value over which the nucleation rate surpasses the mixing velocity, so that $\Omega$ is limited by crystal precipitation (Söhnel and Mullin, 1987; Philips et al., 1999; Kile et al., 2000; Vicum et al., 2003; Schwarzer and Peukert, 2004). As a result the first nucleating particles grow while further nuclei are simultaneously generated. The longer the period of nucle- 
ation the higher the resulting crystal size variance $\left(\beta^{2}\right)$ (Philips et al., 1999). For a given nominal supersaturation and mixing velocity (as applied in this work), the period in which nucleation and growth coexist depends on the induction time $(\tau)$ for nucleation, because the shorter the induction time the higher the number of nucleation events during the "mixing period". As a consequence, $\beta^{2}$ is proportional to $\tau^{-1}$. Moreover, as $\tau$ is inversely proportional to the nucleation rate, $\beta^{2}$ results to be an indication of the nucleation kinetics. The variance of the CSD yields information about nucleation and initial growth conditions because, during the first few nanometers of growth (as relevant for our experiments), the $\beta^{2}$ changes in response to solution chemistry (Eberl et al., 1998).

The observation that means crystal size decreases with increasing $\beta^{2}$ (for different chloride salts at constant $\Omega$ ) is consistent with conclusion that in the investigated system $\beta^{2}$ tracks nucleation rates. In our experiments the only variable (for a given $\Omega$ and IS) is the background electrolyte. Therefore differences in the kinetics of barium sulfate crystallization and consequent crystal size variance and mean crystal size result from the influence of background ions.

\subsection{Frequency of water exchange as rate-limiting factor for nucleation}

According to the classical nucleation theory increasing the supersaturation and/or reducing the solid-liquid interfacial tension lowers the nucleation barrier. The height of the nucleation barrier, in the case of spherical nuclei, is expressed by free energy of formation of critical nuclei:

$\Delta G^{*}=\frac{16 \pi}{3} \gamma^{3} / \rho|\Delta \mu|^{2}$,

where $\gamma$ is the solid-liquid interfacial tension, $\rho$ is the number density of a crystal phase, $\Delta \mu=\mu\left(\mathrm{BaSO}_{4}\right)_{(\mathrm{s})}-$ $\mu\left(\mathrm{Ba}^{2+}\right)_{(\mathrm{aq})}-\mu\left(\mathrm{SO}_{4}^{2-}\right)_{(\mathrm{aq})}$ (where $\mu$ designates the chemical potential of respective species in the solid (s) and the liquid state (aq)). The rate $J$ at which nuclei are formed depends exponentially on $\Delta G^{*}$ :

$J=\kappa \exp \left(-\Delta G^{*} / k_{B} T\right)$

where $k_{B}$ is Boltzmann's constant and $\kappa$ is a kinetic prefactor.

Our experimental observations suggest that nucleation rates of barite (as predicted by $\beta^{2}$ ) vary in different background electrolytes regardless of the same $\Omega$ (i.e. constant $\Delta \mu$ ) (Table 1 and Fig. 5). Therefore, from Eq. (2), differences in the nucleation rates of barite are determined by differences in the kinetic barrier for nucleation $(\kappa)$ and/or surface tension $(\gamma)$. The kinetic prefactor $(\kappa)$ is proportional to the diffusion coefficient of crystal building units (Walton, 1969; Jones et al., 2005). Diffusion of ions in aqueous solutions is determined by the frequency of water exchange $\left(f_{\mathrm{H} 2 \mathrm{O}}\right)$ between an ion solvation shell and a bulk fluid (Lee and Rasaiah, 1994, 1996; Chong and Hirata, 1999; Rasaiah and Lynden-Bell, 2001; Du et al., 2007), which depends on the competition between the tendency of the ion to orient water molecules in its solvation shell and the tendency of the water to preserve its hydrogen-bonded net- work (Hribar et al., 2002). Solid-liquid interfacial tension is also defined by the competition between cohesive forces of the liquid and adhesive forces between water molecules and the solid surface. Therefore $f_{\mathrm{H} 2 \mathrm{O}}$ (hence $\kappa$ ) and $\gamma$ are in fact correlated. A longer residence time of water in the vicinity of an ion (as a result of enhanced ion-water or reduced water-water affinity) means a less favorable $\kappa$ but lower interfacial tension. This implies that the same changes in solution can cause opposite effects on nucleation rate. This is in agreement with AFM (Kowacz et al., 2007) and molecular simulation studies (Piana et al., 2006; Jones et al., 2008) that have shown that addition of methanol to an aqueous solution increases kinetics of two-dimensional (2D) nucleation on a barite surface in spite of the increase in $\gamma$. These findings were attributed to the reduced kinetic barrier of cation desolvation as a result of the strengthening of H-bonds in the aqueous solvent. The frequency of water exchange around crystal building units was then suggested to be the rate-limiting factor for surface-controlled 2D nucleation of barium sulfate (Kowacz and Putnis, 2008) because it defines the probability of contact of the ion in its "dehydrated state" with the crystal surface. Such an effective contact, the starting point for a nucleation event, can mean that an ion is moved to a position where it shares its water of solvation with the surface (or with another ion in solution) so that its position at the surface (or in the vicinity of the ion) is stabilized with respect to its residence in the bulk. The results presented here suggest that ion dehydration rates also control three-dimensional nucleation of barite in solution.

\subsection{Long range electrostatic interactions and short range hydration forces as controls of water exchange frequency}

The dependence of the nucleation rates of barite (as indicated by $\beta^{2}$ ) on the background salt (at given $\Omega$ and IS) and the relative switchover in the effect of respective electrolytes on nucleation kinetics between the two studied $\Omega$ (and IS) conditions (Fig. 5) can be explained by considering factors affecting dehydration rates of ions immersed in electrolyte solution. The dehydration and association of ions will be affected by the facility to strip water molecules from the ion solvation shell and by the tendency of the structured fluid to exclude ions from its $\mathrm{H}$-bonded network.

The frequency of water exchange $\left(f_{\mathrm{H} 2 \mathrm{O}}\right)$ around an ion is defined by the ratio $\left(\tau_{i} / \tau_{0}\right)$ of the residence time of a water molecule in the closest position to the ion $\left(\tau_{i}\right)$, to the residence time of water in the bulk $\left(\tau_{0}\right)$. In electrolyte solution the potential energy of a water molecule oriented in an ion solvation shell (here we consider $\mathrm{Ba}^{2+}$ and $\mathrm{SO}_{4}{ }^{2-}$ ) is lowered by attractive interaction between the partial charge of the water dipole and the unlike electric field of counterions (components of background salt) (Samoilov, 1967, 1971). As a result the position of a water of solvation of an ion immersed in electrolyte solution is stabilized and the residence time of this water $\left(\tau_{i-\text { salt }}\right)$ increases in salt solution in comparison to pure water $\left(\tau_{i}\right)$ (Kinoshita and Harano, 2005).

The mean time during which two solvent molecules stay in the immediate vicinity of each other in the electrolyte solution $\left(\tau_{0-\text { salt }}\right)$ depends on the effect of the electrolyte on 
water structure dynamics. The higher the potential of background ions to orient water in their solvation shells (hydration) the more retarded is the mobility of water molecules in solution $\left(\tau_{0-\text { salt }}\right.$ increases). When high charge density of the ion retards water mobility in its vicinity compared to mobility within the hydrogen-bonded network of bulk water $\left(\tau_{i}>\tau_{0}\right)$ the hydration of an ion is defined as "positive". Examples are $\mathrm{Na}^{+}, \mathrm{Li}^{+}$and $\mathrm{F}^{-}$. When the water mobility is increased in its vicinity compared to in the bulk $\left(\tau_{i}<\tau_{0}\right)$ the hydration of an ion is "negative", e.g. $\mathrm{K}^{+}$, $\mathrm{Cl}^{-}, \mathrm{Br}^{-}$(Samoilov, 1965).

At IS $=0.03 \mathrm{M}$ (lower electrolyte concentration) the $f_{\mathrm{H} 2 \mathrm{O}}$ around $\mathrm{Ba}^{2+}$ and $\mathrm{SO}_{4}{ }^{2-}$ (hence diffusion of the ions) is controlled by the "electrostatic environment", which is related to the nature of the background electrolyte, particularly to the tendency to form ion pairs $\left(\mathrm{KCl}_{(\mathrm{aq})}, \mathrm{NaCl}_{(\mathrm{aq})}\right.$, etc.). For simple 1:1 electrolytes this tendency is related to the electrolyte solubility: the lower the solubility the higher the tendency of the electrolyte cations and anions to pair (Collins, 1995, 1997), which decreases the effect of their charges on the residence time of water of hydration $\left(\tau_{i-\text { salt }}\right)$ and thus on the mobility of $\mathrm{Ba}_{2+}$ and $\mathrm{SO}_{4}{ }^{2-}$. Therefore the mobility of $\mathrm{Ba}^{2+}$ and $\mathrm{SO}_{4}{ }^{2-}$ is higher in less soluble salts and the nucleation rate of barite increases with decreasing solubility of background electrolyte (Fig. 6).

Ion distribution in solution (and solubility of simple ionic salts) depends on hydration characteristics. Similarly hydrated ions tend to associate while oppositely-hydrated ions tend to stay apart in solution (Hawlicka and SwiatlaWojcik, 2003; Collins et al., 2007). As a result the kinetics of barite nucleation is faster in background salts composed by ions of the same (positive-positive or negative-negative) hydration compared to salts composed of ions of opposite (positive-negative) hydration. This can be illustrated by the noticeably higher $\beta^{2}$ in $\mathrm{KCl}$ with respect to $\mathrm{NaCl}$ as background electrolyte regardless of a very small difference in the solubility of these salts (Fig. 6).

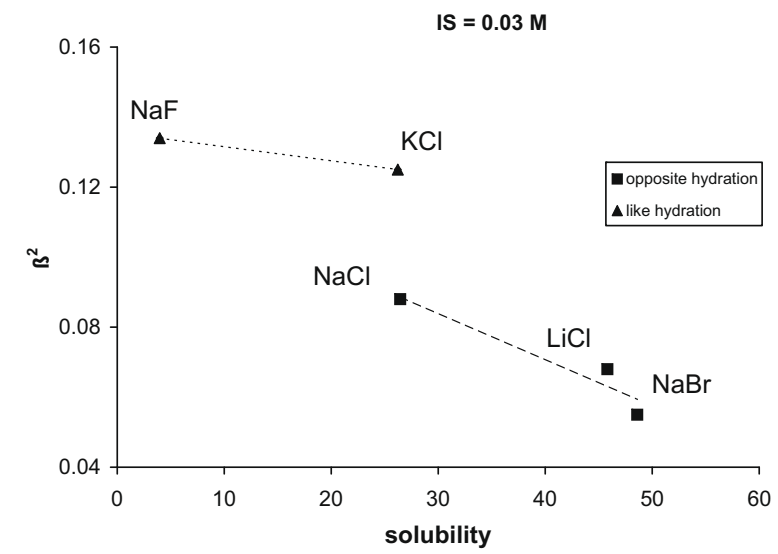

Fig. 6. Crystal size variance $\left(\beta^{2}\right)$ of barium sulfate precipitate as a function of solubility of background salt at ionic strength $\left(\right.$ IS) $=0.03 \mathrm{M}$ and supersaturation $(\Omega)=10^{3.33}$. Trend lines follow $\beta^{2}$ in salts composed of ions of the same ("like-hydration"- $\mathrm{NaF}$, $\mathrm{KCl}$ ) and unlike ("opposite-hydration"- $\mathrm{NaBr}, \mathrm{LiCl}, \mathrm{NaCl}$ ) hydration characteristics. Solubility is expressed as a mass percent of solute (Lide, 2004).
At IS $=0.09 \mathrm{M}$ (higher electrolyte concentration), where electrostatic interactions are suppressed and hydration shells overlap, the differences in the $f_{\mathrm{H} 2 \mathrm{O}}$ around $\mathrm{Ba}^{2+}$ and $\mathrm{SO}_{4}{ }^{2-}$ in respective background electrolytes are no longer controlled by the "electrostatic environment" (ion charge distribution) but by the effect of the electrolyte ions on the bulk solvent structure dynamics $\left(\tau_{0-\text { salt }}\right)$. The higher the affinity of water to other solvent molecules (other waters or ions) in electrolyte solution, the less mobile and less prone the water will be to hydrate solutes $\left(\mathrm{Ba}^{2+}\right.$ and $\mathrm{SO}_{4}{ }^{2-}$ ) immersed in the electrolyte solution. Therefore, nucleation rates of barite increase with increasing positive hydration of background cation (the anion is common for all background electrolytes) (Fig. 7). This can be understood from the perspective of the competition for hydration water between background ions and barite building units: the higher the competition the faster the frequency of water exchange. Such a conclusion is consistent with Raman spectral studies showing the effect of hydration of counterion $\left(\mathrm{Rb}^{+}, \mathrm{Cs}^{+}, \mathrm{K}^{+}, \mathrm{Na}^{+}, \mathrm{Li}^{+}\right)$on frequency of water exchange around $\mathrm{SO}_{4}{ }^{2-}$ (Rull and Ohtaki, 1997). The difference in the effect of background ions on the nucleation rate of barite is the most strongly expressed between solutions of chloride salt of negatively hydrated $\mathrm{K}^{+}$and solutions of chloride salts of positively hydrated $\mathrm{Na}^{+}$and $\mathrm{Li}^{+}$. The effect of positively hydrated ions is very similar in spite of the significant difference in their hydration energy. Nevertheless the mobility of water in electrolyte solutions (therefore the residence time of water in the vicinity of other water molecules) depends not only on the energy of ion-water

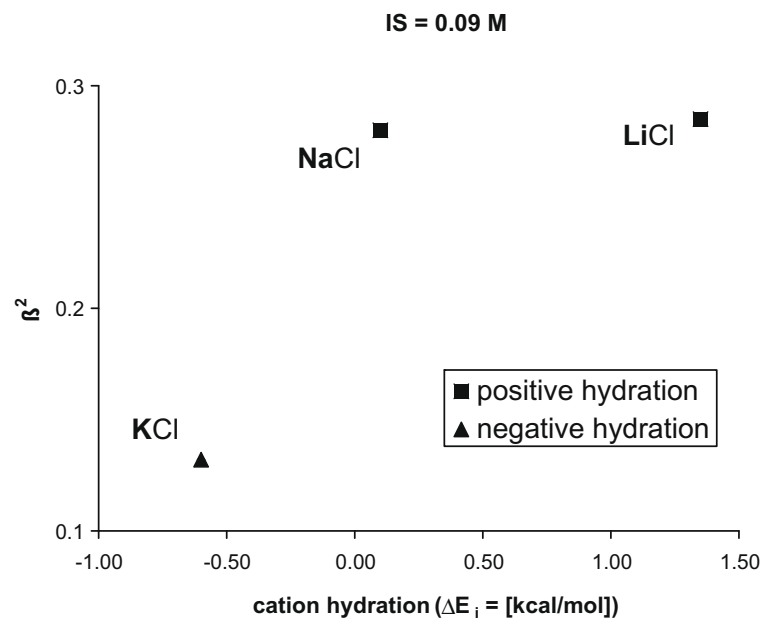

Fig. 7. Crystal size variance $\left(\beta^{2}\right)$ of barium sulfate precipitate as a function of hydration $\left(\Delta E_{i}\right)$ of background cation $\left(i=\mathrm{K}^{+}, \mathrm{Na}^{+}\right.$, $\mathrm{Li}^{+}$) of respective chloride salt at ionic strength (IS) $=0.09 \mathrm{M}$ and supersaturation $(\Omega)=10^{3.77}$. Hydration values are taken from Chong and Hirata (1997) and expressed as a difference $\left(\Delta E_{i}\right)$ in the activation energy of removing a water molecule from the ion solvation shell $\left(E_{i}\right)$ and the activation energy of transferring a water molecule from the first to the next coordination shell of another water molecule $\left(E_{0}\right)$, i.e. $\Delta E_{i}=E_{i}-E_{0}$ (Samoilov, 1965). $\Delta E_{i}<0$ corresponds to "negative hydration" (enhanced translational motion of water molecules in the vicinity of the ion, $\tau_{i}<\tau_{0}$ ) and $\Delta E_{i}>0$ to "positive hydration" (retarded water mobility in the adjacent environment of the ion, $\tau_{i}>\tau_{0}$ ). 
interaction, but is defined by the structure of water modified by the ion (Koneshan et al., 1998). Experimental results show that the mobility of water is significantly different in $\mathrm{KCl}$ solution in comparison to the relatively small differences in water mobility in $\mathrm{NaCl}$ and $\mathrm{LiCl}$ (Ionov and Mazitov, 1968).

The inversion in the influence of different chloride salts on the reactivity of barite with increasing ionic strength is consistent with our previous AFM observations (Kowacz and Putnis, 2008). Such an effect can be explained by considering the fact that the frequency of water exchange around solute ions (here $\mathrm{Ba}^{2+}$ and $\mathrm{SO}_{4}{ }^{2-}$ ) is a result of a competition between the tendency of the solute to orient water in its solvation shell and the tendency of a solvent to preserve its structure, both factors that are affected by different properties of the electrolyte solution. The solutewater affinity is affected by propagation of electric fields of background ions, the property that is most expressed at low ionic strength conditions. The dynamics of the solvent structure is affected by the hydration characteristics of the individual background ions, the property that becomes most pronounced at higher ionic strength. The relative switchover between long range electrostatic interactions and short range hydration forces is in agreement with the fact that in the limit of dilute solutions, thermodynamic properties of electrolytes can be approximated by continuum electrostatics, but when the ionic strength is greater than $\sim 1 \times 10^{-2} \mathrm{M}$, charge propagation (Debye length) is comparable or smaller than the size of water molecules (Akiyama et al., 2007) and the thermodynamic behavior of the electrolyte depends significantly on the effect of ions on solvent structure and dynamics (Conway and Ayranci, 1999; Petsev and Vekilov, 2000; Kunz et al., 2004; Collins et al., 2007).

\subsection{Activation energy of nucleation and growth}

The information about the nucleation rate and the amount of barite precipitate that has been generated in solutions of different background electrolytes allows us to extract some information about the relative input of the nucleation vs. growth process in solid formation in respective solutions. The calorimetric study then provides information about the energetical response of the system to specific processes in crystal formation. This data is then correlated with the relationship between the fundamental steps in the crystallization process and the respective phenomena involving rearrangement of solvent molecules around solutes and around other solvent molecules in the bulk.

The relative amounts of $\left[\mathrm{Ba}^{2+}\right]$ that have been consumed during the crystallization process (assumed to be proportional to the amount of precipitate) correlates with solubility at lower ionic strength and hydration of the background electrolyte at higher ionic strength conditions and therefore with predicted nucleation rates (Figs. 8 and 9).

However the correlation between the solubility of the background salt and the relative amount of barium sulfate precipitate follows different trend lines for the crystallization process in salts composed of oppositely-hydrated (i.e. $\mathrm{NaBr}, \mathrm{LiCl}$ and $\mathrm{NaCl}$ ) and like-hydrated (i.e. $\mathrm{KCl}$ and

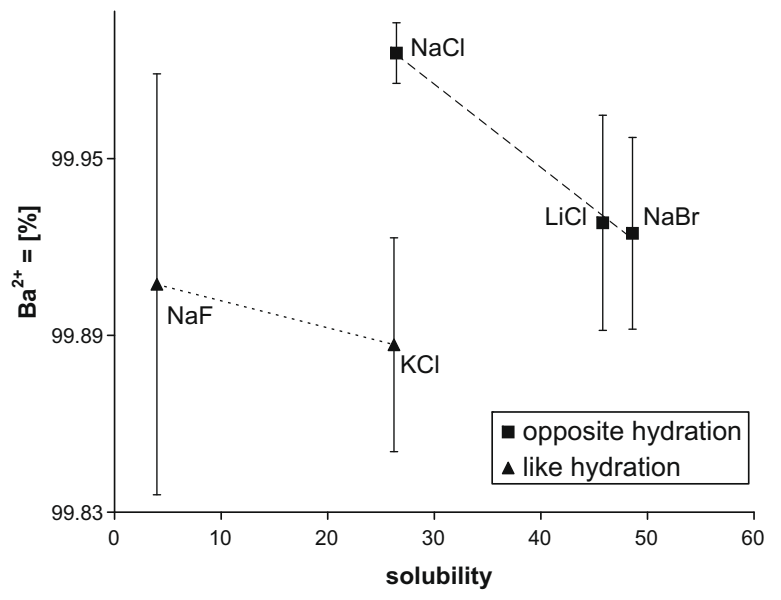

Fig. 8. Relative amounts of $\mathrm{Ba}^{2+}$ (as a percent of initial $\mathrm{Ba}^{2+}$ concentration in solution) consumed during crystallization process as a function of solubility of background salt at ionic strength (IS) $=0.03 \mathrm{M}$ and supersaturation $(\Omega)=10^{3.33}$. Amount of $\mathrm{Ba}^{2+}$ represents an average value from the precipitation experiments in the presence of the respective background salt, and the error bars represent one standard deviation about that mean.

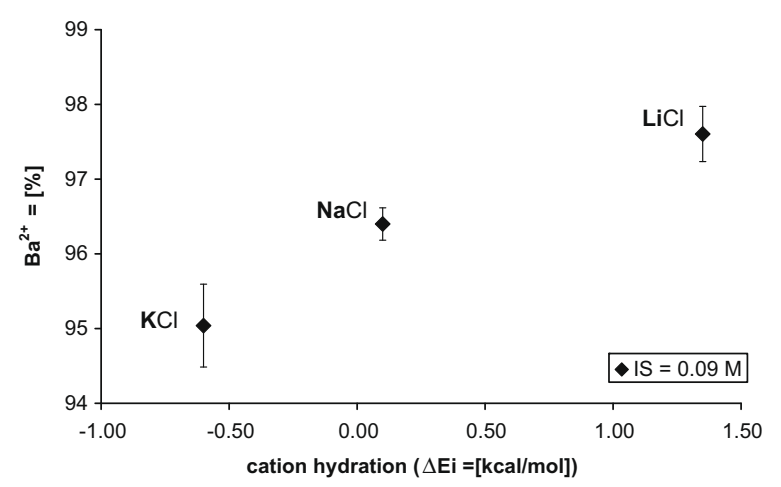

Fig. 9. Relative amounts of $\mathrm{Ba}^{2+}$ (as a percent of initial $\mathrm{Ba}^{2+}$ concentration in solution) consumed during crystallization process as a function of hydration $\left(\Delta E_{i}\right)$ of background cation $\left(i=\mathrm{K}^{+}\right.$, $\mathrm{Na}^{+}, \mathrm{Li}^{+}$) of respective chloride salt at ionic strength (IS) $=0.09 \mathrm{M}$ and supersaturation $(\Omega)=10^{3.77}$. Amount of $\mathrm{Ba}^{2+}$ represents an average value from the precipitation experiments in the presence of the respective background salt, and the error bars represent one standard deviation about that mean.

$\mathrm{NaF}$ ) ions. Less precipitate is generated in like-hydrated (more associated) salts, in which nucleation rates of barite are higher, which suggests that $\Omega$ in these solutions is reduced more by nucleation and less by growth compared to precipitation in oppositely-hydrated salts and precipitate mass is added mainly by growth. The heat of barium sulfate precipitation $\left(Q_{\mathrm{BaSO} 4}\right)$ results from the net effect of nucleation and growth and generally increases with increasing amount of precipitate (Fig. 10).

However at lower $\Omega$ and lower IS conditions the dependence of $Q_{\mathrm{BaSO} 4}$ on the amount of precipitated solid follows different trends for like-hydrated and oppositely-hydrated background salts, with relative dominance of nucleation in the former and growth in the latter (Fig. 11). 


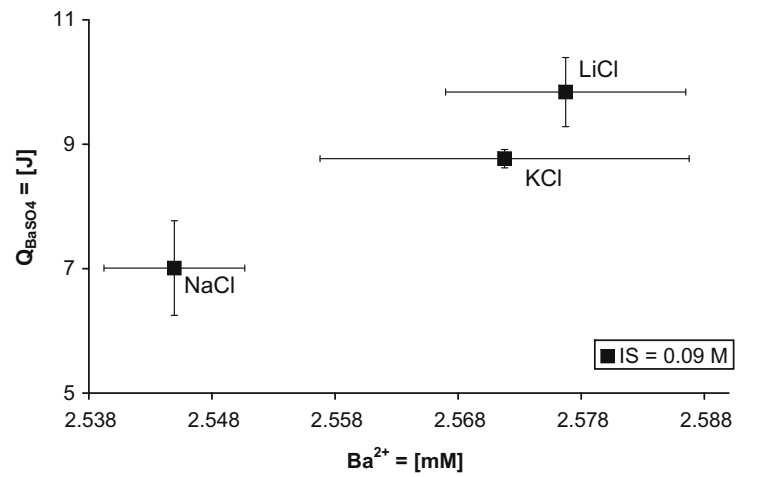

Fig. 10. Heat of barium sulfate precipitation $\left(Q_{\mathrm{BaSO}}\right)$ as a function of concentration of $\mathrm{Ba}^{2+}$ consumed during crystallization process at ionic strength (IS) $=0.09 \mathrm{M}$ and supersaturation $(\Omega)=10^{3.77}$. $Q_{\mathrm{BaSO} 4}$ and $\left[\mathrm{Ba}^{2+}\right]$ represent average values from the precipitation experiments in the presence of the respective background salt, and the error bars represent one standard deviation about that mean.

Barite crystallization seems to be more exothermic in like-hydrated electrolytes (the trend line for $Q_{\mathrm{BaSO} 4}$ as a function of precipitate concentration is shifted towards higher values on the $y$-axis) which implies that nucleation gives a more positive heat signal than growth. Due to the significant experimental variability, the relationship based on the average values of $Q_{\mathrm{BaSO} 4}$ and $\left[\mathrm{Ba}^{2+}\right]$ can be questioned. Nevertheless it was shown that the dependence of the rate of nucleation (this work) and growth (Kowacz and Putnis, 2008) of barite on properties of the electrolyte solution also follows different trends for like and oppositely-hydrated salts. This observation together with the fact that kinetics of nucleation and growth of barite change differently in response to the same changes in solution composition (Kowacz et al., 2007; Kowacz and Putnis, 2008) supports the suggestion that the energetical costs of these

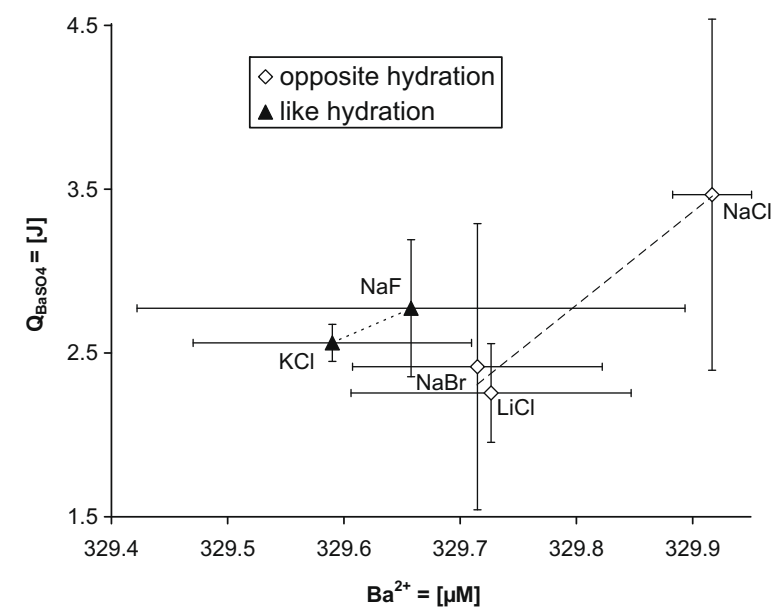

Fig. 11. Heat of barium sulfate precipitation $\left(Q_{\mathrm{BaSO}}\right)$ as a function of concentration of $\mathrm{Ba}^{2+}$ consumed during crystallization process at ionic strength (IS) $=0.03 \mathrm{M}$ and supersaturation $(\Omega)=10^{3.33}$. $Q_{\mathrm{BaSO} 4}$ and $\left[\mathrm{Ba}^{2+}\right]$ represent average values from the precipitation experiments in the presence of the respective background salt, and the error bars represent one standard deviation about that mean. elementary steps can be different. This can result from the proposed differences in the kinetic barriers for nucleation and ion addition at kinks (Kowacz and Putnis, 2008). Growth of barite was assumed to be limited by the energy required to remove water molecules hydrating the ion and the surface while nucleation is limited by the probability of contact of building units in a "dehydrated state" i.e. by the frequency of water exchange that determines dehydration rates and mobility of ions in solution. Therefore if we treat water exchange as a spontaneous thermal fluctuation (Zhang et al., 2007), the energetic costs of a nucleation event can be lower than that of ion attachment on the crystal surface. However, ion incorporation at kinks is more frequent because it is stabilized by strong electrostatic interactions with neighboring molecules within the crystal structure. Yet Coulombic forces can be insufficient to overcome the energy barrier of dehydration and stabilize the ion position on a flat terrace or next to another ion in solution.

\subsection{Weakly hydrated ions and heterogeneous nucleation}

The tendency of the structured solvent to exclude ions from its H-bonded network affects not only barite building units but also background ions present in solution. The solutions are undersaturated with respect to background salts, therefore those do not precipitate, but composing ions can associate in solution (Hawlicka and Swiatla-Wojcik, 2003) and separate from bulk water structure. Our findings suggest that such phenomena can have implications for heterogeneous nucleation of barite in solution.

In our experiments the size of barite crystals precipitated in different background sodium salts seems to be unaffected by changes in nucleation rates (as inferred from independence of size on $\beta^{2}$ at constant $\Omega$ ) and for $\mathrm{NaCl}$ as a background electrolyte crystal size does not depend on supersaturation (for $\Omega=10^{3.33}$ and $\Omega=10^{3.47}$ ) (Fig. 5). Constant nucleus size regardless of increasing solution supersaturation $(\Omega)$ was observed for $\mathrm{BaSO}_{4}$ precipitation in the presence of $\mathrm{NaCl}$ and interpreted as an indication of the dominant influence of heterogeneous nucleation $(\mathrm{Ku}-$ cher et al., 2006). At constant $\Omega$, increasing nucleation kinetics should also result in precipitation of a higher amount of smaller particles. Therefore the independence of particle size on nucleation rates and on the saturation state of the solution observed in our experiments, implies the predominance of heterogeneous nucleation in the precipitation of the solid. This is consistent with the fact that the lower investigated supersaturation level $\left(\Omega=10^{3.33}\right)$ represents the borderline conditions between homogeneously and heterogeneously dominated nucleation of barite (He et al., 1995).

The experimental observation that $\mathrm{Na}^{+}$can be incorporated into the barite structure when present in solution as a salt of strongly hydrated anions (Kowacz and Putnis, 2008) suggests a possible explanation for the role of $\mathrm{Na}^{+}$in the nucleation process. Sodium incorporation was attributed to the fact that this weakly hydrated ion is preferentially excluded from the aqueous solvent with increasing solventsolvent affinity. The tendency of an ion to separate from the bulk water structure leads to ion segregation at the 
air/water interface (Jungwirth and Tobias, 2001, 2002; Garret, 2004; Ghosal et al., 2005; Manciu and Ruckenstein, 2005) or other interfaces (Collins, 1995) that can potentially serve as charged nucleation centers. The less hydrated the ion (the lower its charge to radius ratio) the higher the tendency to separate it from the structured aqueous solvent. Therefore the suggested mechanism for heterogeneous nucleation should be more strongly expressed with diminishing hydration of ions. This is in agreement with the experimental observation that barite nucleation rates in the heterogeneous region increase with increasing radius of monovalent ions $\left(\mathrm{Na}^{+}<\mathrm{K}^{+}<\mathrm{Cs}^{+}<\left(\mathrm{CH}_{3}\right)_{4} \mathrm{~N}^{+}\right) \quad(\mathrm{He}$ et al., 1995).

\subsection{Solvent structure dynamics, kinetics of nucleation and crystal size}

Control of the water structure dynamics on the kinetics of barite nucleation results in differences in the dependence of nucleation rates on supersaturation between solutions of background salts of distinct hydration characteristics (as inferred from changes of $\beta^{2}$ with $\Omega$ ). This is expressed by only a minor increase in barite nucleation rates with increasing $\Omega$ in the chloride salt of negatively hydrated potassium, and a relatively sharp increase of nucleation kinetics in chloride salts of positively hydrated sodium and lithium (Fig. 5). Negatively hydrated $\mathrm{K}^{+}$ions reduce the affinity of water to other solvent molecules $\left(\tau_{0-\mathrm{KCl}}\right.$ decreases with concentration) which results in a higher degree of ordering of water molecules around a solute molecule immersed in $\mathrm{KCl}$ solution as the electrolyte concentration increases. On the contrary, positively hydrated $\mathrm{Li}^{+}$and $\mathrm{Na}^{+}$ions retard water mobility and therefore increase the average time that a solvent molecule spends in the bulk electrolyte solution $\left(\tau_{0-\mathrm{NaCl}}\right.$ and $\tau_{0-}$ $\mathrm{LiCl}$ increase with concentration) with respect to its residence time in the solute solvation shell. As a consequence, the frequency of water exchange around respective building units (i.e. the suggested rate-limiting factor for barium sulfate nucleation) increases with increasing $\mathrm{KCl}$ concentration and decreases with increasing $\mathrm{LiCl}$ and $\mathrm{NaCl}$ concentration in solution. This is in agreement with the respective changes in solution enthalpy of $\mathrm{BaCl}_{2}\left(\Delta H_{\mathrm{BaCl} 2}\right)$ in solutions of different background electrolytes (Table 2). $\Delta H_{\mathrm{BaCl} 2}$ expresses the relative differences between barium-water and water-water attractions, and therefore the enthalpy of solution data can indicate differences in the water exchange around $\mathrm{Ba}^{2+}$ in different background salts. At the same time the kinetic barrier for growth increases at higher IS in all background salts, due to electrostatic stabilization of water hydrating barite building units in solution and at crystal surface. This is expressed in the less negative enthalpy of precipitation at $\mathrm{IS}=0.09 \mathrm{M}$ (Table 1).

At higher $\Omega$ more material is brought into the reacting system, increasing the flux of ions into the surface and the probability of effective contact of building units in the bulk. Therefore growth and nucleation rates increase. Nevertheless because of the strong dependence of nucleation rate and critical nucleus size on supersaturation, the particle size is expected to diminish with increasing $\Omega$. However in our experiments this is only the case with $\mathrm{LiCl}$ as a background electrolyte, while in negatively hydrated $\mathrm{KCl}$ a significant increase in crystal size at higher supersaturation (and ionic strength) can be actually observed. For colloidal systems an increase in the crystallite size at larger supersaturations was recently attributed to the fact that the probability of formation of critical nuclei goes through a maximum as the $\Omega$ is increased because of the increase of solid-liquid interfacial tension (Auer and Frenkel, 2001), in contrast to the interpretation explaining crystal size as the effect of heterogeneous nucleation. Our findings suggest that the increase of barite particle size with increasing $\Omega$ can result from a solutiondependent kinetic barrier for nucleation which suppresses the dependence of nucleation rates on $\Omega$. Furthermore, growth rates of barite (in the region where two-dimensional nucleation is not rate limiting) were suggested to be determined by the energetic costs of expelling waters of solvation and not by the frequency of water exchange (Kowacz and Putnis, 2008). It is worth noting that the residence time of water in an ion solvation shell can be relatively long, depending on the solvent structure dynamics, regardless of the weak electrostatic ion-water attractions (Koneshan et al., 1998). Because of the differences in kinetic barriers for nucleation and for ion attachment at kinks, growth can be more favored than nucleation at higher $\Omega$, thus increasing crystal size. This can be the case in solutions where the dynamics of the aqueous solvent structure increases with $\Omega$, for example as a result of addition of negatively hydrated solutes. Our observations are in agreement with other experimental results that have shown that increasing the concentration of the chloride salt of the negatively hydrated potassium ion increases the linear growth rate of barite, while chloride salts of positively hydrated sodium and calcium ions mainly increase nucleation rates (Matynia et al., 2004).

\section{CONCLUSIONS}

Our findings suggest that nucleation rates of barite and the resulting precipitate characteristics such as mean crystal size and crystal size variance can be modified by background salts present in solution, due to the effects of these electrolytes on the dynamics of the bulk aqueous solvent structure and on the water of solvation. The results presented here support the hypothesis that the frequency of water exchange, which determines the diffusion of ions in solution, is the kinetic barrier for the nucleation process of barium sulfate (Kowacz and Putnis, 2008). The resulting dependence of the nucleation kinetics on solvent structure dynamics allows the prediction of the effect of aqueous solvent properties on the crystallization process. Our results imply that weakening water-water interactions will suppress nucleation kinetics while increasing water affinity to other water molecules will assist nucleation kinetics. Our conclusions are consistent with experimental observations such as the enhanced nucleation rates of barite by addition of methanol (Tomson et al., 2005) which reduces water structure dynamics and consequently lowers the kinetic barrier of the cation desolvation (Piana et al., 2006). Identification of the kinetic barriers for crystal nucleation and growth and recognition of their dependence on solution composition suggests that it is possible to selectively control 
fundamental steps in the crystallization process by adjusting solution composition. Such knowledge can add to our understanding of the influence of additives on crystal precipitation and should be helpful in designing a solvent with desirable impact on crystallization product characteristics.

\section{ACKNOWLEDGMENTS}

The experimental work was carried out at Department of Geology at University of Oviedo within the EU Early Stage Training Network MIR (Mineral-fluid Interface Reactivity) Contract No. MEST-CT-2005-021120.

\section{REFERENCES}

Akiyama R., Fujino N. and Kinoshita M. (2007) Interaction between like-charged colloidal particles in aqueous electrolyte solution: attractive component arising from solvent granularity. Condens. Matter Phys. 10, 587-596.

Auer S. and Frenkel D. (2001) Suppression of crystal nucleation in polydisperse colloids due to increase of the surface free energy. Nature 413, 711-713.

Chong S.-H. and Hirata F. (1997) Ion hydration: thermodynamic and structural analysis with an integral equation theory of liquids. J. Phys. Chem. 101, 3209-3220.

Chong S.-H. and Hirata F. (1999) Dynamics of ions in liquid water: an interaction-site-model description. J. Chem. Phys. 111, 3654-3667.

Collins K. D. (1995) Sticky ions in biological systems. Proc. Natl. Acad. Sci. USA 92, 5553-5557.

Collins K. D. (1997) Charge density-dependent strength of hydration and biological structure. Biophys. J. 72, 65-76.

Collins K. D., Neilson G. W. and Enderby J. E. (2007) Ions in water: characterizing the forces the control chemical processes and biological structure. Biophys. Chem. 128, 95-104.

Conway B. E. and Ayranci E. (1999) Effective ionic radii and hydration volumes for evaluation of solution properties and ionic adsorption. J. Solut. Chem. 28, 163-192.

De Yoreo J. J. and Dove P. M. (2004) Shaping crystals with biomolecules. Science 303, 1301.

Dove P. M., Han N. and De Yoreo J. J. (2005) Mechanisms of classical crystal growth theory explain quartz and silicate dissolution behavior. Proc. Natl. Acad. Sci. USA 102, 1535715362.

Du H., Rasaiah J. C. and Miller J. D. (2007) Structural and dynamic properties of concentrated alkali halide solutions: a molecular dynamics simulation study. J. Phys. Chem. B 111, 209-217.

Eberl D. D., Drits V. A. and Srodon J. (1998) Deducing growth mechanisms for minerals from the shapes of crystal size distributions. Am. J. Sci. 298, 499-533.

Eberl D. D., Drits V. A., Srodon J. (2000) User's guide to Galoper-a program for simulating the shapes of crystal size distributions - and associated programs. U.S. Geological Survay Open-File Report 00-505.

Eberl D. D., Kile D. E. and Drits V. A. (2002) On geological interpretations of crystal size distributions: constant vs. proportionate growth. Am. Mineral. 87, 1235-1241.

Elhadj S., De Yoreo J. J., Hoyer J. R. and Dove P. M. (2006) Role of molecular charge and hydrophilicity in regulating the kinetics of crystal growth. Proc. Natl. Acad. Sci. USA 103, 19237-19242.

Garret B. C. (2004) Ions at air/water interface. Science 303, 11461147.

Ghosal S., Hemminger J. C., Bluhm H., Mun B. S., Hebenstreit E. L. D., Ketteler G., Ogletree D. F., Requejo F. G. and Salmeron
M. (2005) Electron spectroscopy of aqueous solution interfaces reveals surface enhancement of halides. Science 307, 563-566.

Hawlicka E. and Swiatla-Wojcik (2003) Aggregation of ions in methanol-water solutions of sodium halides. J. Chem. Phys. 119, 2206-2213

He S., Oddo J. E. and Tomson M. B. (1995) The nucleation kinetics of barium sulfate in $\mathrm{NaCl}$ solutions up to $6 \mathrm{M}$ and $90^{\circ} \mathrm{C}$. J. Colloid Interface Sci. 174, 319-326.

He B. H. (2005) Introduction to two-dimensional X-ray diffraction. In Proceedings of the Two-dimensional XRD Workshop, 54th Annual Denver X-ray Conference, Colorado Springs.

Hribar B., Southall N. T., Vlachy V. and Dill K. A. (2002) How ions affect the structure of water. J. Am. Chem. Soc. 124, 1230212311.

Ionov V. I. and Mazitov R. K. (1968) Influence of ions on the rotation of water molecules in aqueous solutions as a function of temperature. J. Struct. Chem. 9, 895-896.

Jones F., Ogden M. I., Parkinson G. M. and Rohl A. L. (2005) Comparison of the effect inhibitors have on an isostructural pair of salts. Cryst. Eng. Comm. 7, 1-5.

Jones F., Piana S. and Gale J. D. (2008) Understanding of the kinetics of barium sulfate precipitation from water and watermethanol solutions. Cryst. Growth Des. 8, 817-822.

Jungwirth P. and Tobias D. J. (2001) Molecular structure of salt solutions: a new view on the interface with implications for heterogeneous atmospheric chemistry. J. Phys. Chem. B 105, 10468-10472.

Jungwirth P. and Tobias D. J. (2002) Ions at the air/water interface. J. Phys. Chem. B 106, 6361-6373.

Kile D. and Eberl D. D. (2003) On the origin of size-dependent and size-independent crystal growth: influence of advection and diffusion. Am. Mineral. 88, 1514-1521.

Kile D., Eberl D. D., Hoch A. R. and Reddy M. M. (2000) An assessment of calcite crystal growth mechanisms based on crystal size distributions. Geochim. Cosmochim. Acta 64, 2937-2950.

Kinoshita M. and Harano Y. (2005) Potential of mean force between solute atoms in salt solution: effects due to salt species and relevance to conformational transition of biomolecules. Bull. Chem. Soc. Jpn 78, 1431-1441.

Koneshan S., Rasaiah J. C., Lynden-Bell R. M. and Lee S. H. (1998) Solvent structure, dynamics, and ion mobility in aqueous solution at $25^{\circ} \mathrm{C}$. J. Chem. Phys. 102, 4193-4204.

Kowacz M. and Putnis A. (2008) The effect of specific background electrolytes on water structure and solute hydration: consequences for crystal dissolution and growth. Geochim. Cosmochim. Acta 72, 4476-4487.

Kowacz M., Putnis C. V. and Putnis A. (2007) The effect of cation:anion ratio in solution on the mechanism of barite growth at constant supersaturation: role of the desolvation process on the growth kinetics. Geochim. Cosmichim. Acta 71, 5168-5179.

Kucher M., Babic D. and Kind M. (2006) Precipitation of barium sulfate: experimental investigation about the influence of supersaturation and free lattice ion ratio on particle formation. Chem. Eng. Process. 45, 900-907.

Kunz W., Lo Nostro P. and Ninham B. W. (2004) The present state of affairs with Hofmeister effects. Curr. Opin. Colloid Interface Sci. 9, 1-18.

Lee S. H. and Rasaiah J. C. (1994) Molecular dynamics simulation of ionic mobility. 1. Alkali metal cations in water at $25^{\circ} \mathrm{C}$. $J$. Chem. Phys. 101, 6964-6974.

Lee S. H. and Rasaiah J. C. (1996) Molecular dynamics simulation of ion mobility. 2. Alkali metal and halide ions using the SPC/E model for water at $25^{\circ} \mathrm{C}$. J. Chem. Phys. 100, 1420-1425.

Lide D. R. (2004) Aqueous solubility of inorganic compounds at various temperatures. CRC Handbook of Chemistry and Physics, 84th ed., CRC Press/Taylor and Francis, Boca Raton, FL. 
Manciu M. and Ruckenstein E. (2005) On the interactions of ions with the air/water interface. Langmuir 21, 11312-11319.

Marcus Y. (2009) Effect of ions on the structure of water: Structure making and breaking. Chem. Rev. 109, 1346-1370.

Matynia A., Piotrowski K., Koralewska J. and Wierzbowska B. (2004) Barium sulfate crystallization kinetics in the used quenching salt treatment process. Chem. Eng. Technol. 27, $559-568$.

Palka K. and Hawlicka E. (2005) Influence of alcohols on $\mathrm{Ca}^{2+}$ hydration. J. Mol. Liq. 122, 28-31.

Parkhurst D. L. and Appelo C. A. J. (1999) Users guide to PHREEQC (version 2) - a computer program for speciation, batch reaction, one-dimensional transport, and inverse geochemical calculations. U.S. Geological Survey Water-Resources Investigation Report, pp. 99-4259.

Petsev D. N. and Vekilov P. G. (2000) Evidence for non-DLVO hydration interactions in solutions of the protein apoferritin. Phys. Rev. Lett. 84, 1339-1342.

Petsev D. N., Chen K., Gliko O. and Vekilov P. G. (2003) Diffusion-limited kinetics of the solution-solid phase transition of molecular substances. Proc. Natl. Acad. Sci. USA 100, 792796.

Philips R., Rohani S. and Baldyga J. (1999) Micromixing in a single-feed semi-batch precipitation process. AIChE J. 45, 8292.

Piana S., Jones F. and Gale J. D. (2006) Assisted desolvation as a key kinetic step for crystal growth. J. Am. Chem. Soc. 128, 13568-13574.

Piana S., Jones F. and Gale J. D. (2007) Aspartic acid as a crystal growth catalyst. Cryst. Eng. Comm. 9, 1187-1191.

Rasaiah J. C. and Lynden-Bell R. M. (2001) Computer simulation studies of the structure and dynamics of ions and non-polar solutes in water. Phil. Trans. R. Soc. Lond. A 359, $1545-1574$.

Rodríguez-Navarro A. (2006) XRD2DScan: new software for polycrystalline materials characterization using two-dimensional X-ray diffraction. J. Appl. Crystallogr. 39, 905-909.
Rull F. and Ohtaki H. (1997) Raman spectral studies on ionic interaction in aqueous alkali sulfate solutions. Spectrochim. Acta A 53, 643-653.

Samoilov O. Y. (1967) Theory of salting out from aqueous solutions. 1. General problems. J. Struct. Chem. 7, 12-19.

Samoilov O. Y. (1971) Theory of salting out from aqueous solutions. 3. Dependence of salting out on characteristics of ions of salting out agent. J. Struct. Chem. 11, 929-931.

Samoilov O. Ya. (1965) The hydration of ions in aqueous solutions. In Structure of Aqueous Electrolyte Solutions and the Hydration of Ions. Consultants Bureau, New York, pp. 74106.

Schwarzer H.-S. and Peukert W. (2004) Combined experimental/ numerical study on the precipitation of nanoparticles. AIChE J. 50, 3234-3247.

Söhnel O. and Mullin J. W. (1987) Interpretation of crystallization induction periods. J. Colloid Interface Sci. 123, 43-50.

Stephenson A. E., De Yoreo J. J., Wu L., Wu K. J., Hoyer J. and Dove P. M. (2008) Peptides enhance magnesium signature in calcite: insights into origins of vital effects. Science 322, 724 727.

Tomson M. B., Kan A. T. and Fu G. (2005) Inhibition of barite scale in the presence of hydrate inhibitors. SPE J. 10, 256-266.

Vicum L., Mazzotti M. and Baldyga J. (2003) Applying a thermodynamic model to the non-stoichiometric precipitation of barium sulfate. Chem. Eng. Technol. 26, 325-333.

Walton A. G. (1969) Nucleation in liquids and solutions. In Nucleation (ed. A. C. Zettlemoyer). Marcel Dekker Inc., New York., pp. 225-307.

Zhang L., Wang L., Kao Y.-T., Qiu W., Yang Y., Okobiah O. and Zhong D. (2007) Mapping hydration dynamics around a protein surface. Proc. Natl. Acad. Sci. USA 20, 18461-18466.

Zuddas P. and Mucci A. (1998) Kinetics of calcite precipitation from seawater: II. The influence of the ionic strength. Geochim. Cosmochim. Acta 62, 757-766.

Associate editor: Michael Machesky 